\title{
Capitalismo de vigilância: um ensaio performático entre dados, selfies, fetiches e likes
}

Veridiana Zurita é graduada em Comunicação das Artes do Corpo/Dança e Performance / PUC-SP, mestrado em artes visuais pelo Dutch Art Institute - DAI / NL e pós-mestrado em pesquisa artística pelo Advanced Performance Training a.pass/ BE. Trabalha como pesquisadora artística de forma transdisciplinar, através da criação de projetos site-specific, ensaios, vídeo/filme e performance. Entre seus trabalhos mais representativos em termos de metodologia, linhas de pensamento e formulação está o filme Televizinho (2020) e o projeto (Não) Coma o Microfone (desde 2014). Atua também como pesquisadora sobre Tecnovigilantismo e Capitalismo de Vigilância, através da produção e comunicação de conteúdo pelo canal SaiFetiche [Youtube https://www.youtube. com/user/ineedyoutofakeme/featured e Instagram @saifetiche] e ensaios publicados na plataforma jornalística Outras Palavras [https://outraspalavras.net/]. Para conhecer mais, acesse [https://veridianazurita].<veridianazurita@gmail.com> ORCID: 0000-0002-9764-7972
Resumo Esse artigo faz uma costura performática entre o conceito de capitalismo de vigilância, fetichismo da mercadoria e da subjetividade e nossa acelerada auto-sujeição nas redes sociais. A partir do conceito cunhado por Shoshanna Zuboff desdobro a análise sobre capitalismo de vigilância e os limites que apontam as regulamentações da internet como forma de superação dos abusos de poder implicados na coleta, análise e venda de nossos dados. $O$ artigo adentra na esfera subjetiva de nossa quotidiana subordinação às demandas digitais como capital central para esse novo tipo de capitalismo

Palavras chave Capitalismo de vigilância, Subjetividade, Auto-Sujeição, Fetichismo. 


\section{Surveillance capitalism: a performatic essay between data, selfies, fetishes and likes}

Abstract This essay is a performatic seam between the concept of surveillance capitalism, commodity and subjectivity fetishism and our accelerated self-subjection in social networks. Based on the concept coined by Shoshana Zuboff, I unfold the anal$y$ sis of surveillance capitalism and the limits that point to internet regulations as a way of overcoming the abuses of power involved in the collection, analysis and sale of our data. The article enters the subjective sphere of our daily subordination to digital demands as central capital for this new type of capitalism.

Keywords Survaillance capitalism, Subjectivity, Self-Subjection, Fetichism.

Capitalismo de vigilancia: un ensayo performatico entre datos, selfies, fetiches y likes

Resumen Este artículo hace una costura de performance entre el concepto de capitalismo de vigilancia, el fetichismo y la subjetividad de la mercancía y nuestro auto-sometimiento acelerado en las redes sociales. Partiendo del concepto acuñado por Shoshanna Zuboff, desdoblo el análisis del capitalismo de vigilancia y los límites que apuntan a las regulaciones de internet como una forma de superar los abusos de poder involucrados en la recolección, análisis y venta de nuestros datos. El artículo entra en el ámbito subjetivo de nuestra subordinación diaria a las demandas digitales como capital central de este nuevo tipo de capitalismo.

Palabras clave Capitalismo de vigilancia, Subjetividad, Auto-sometimiento, Fetichismo. 

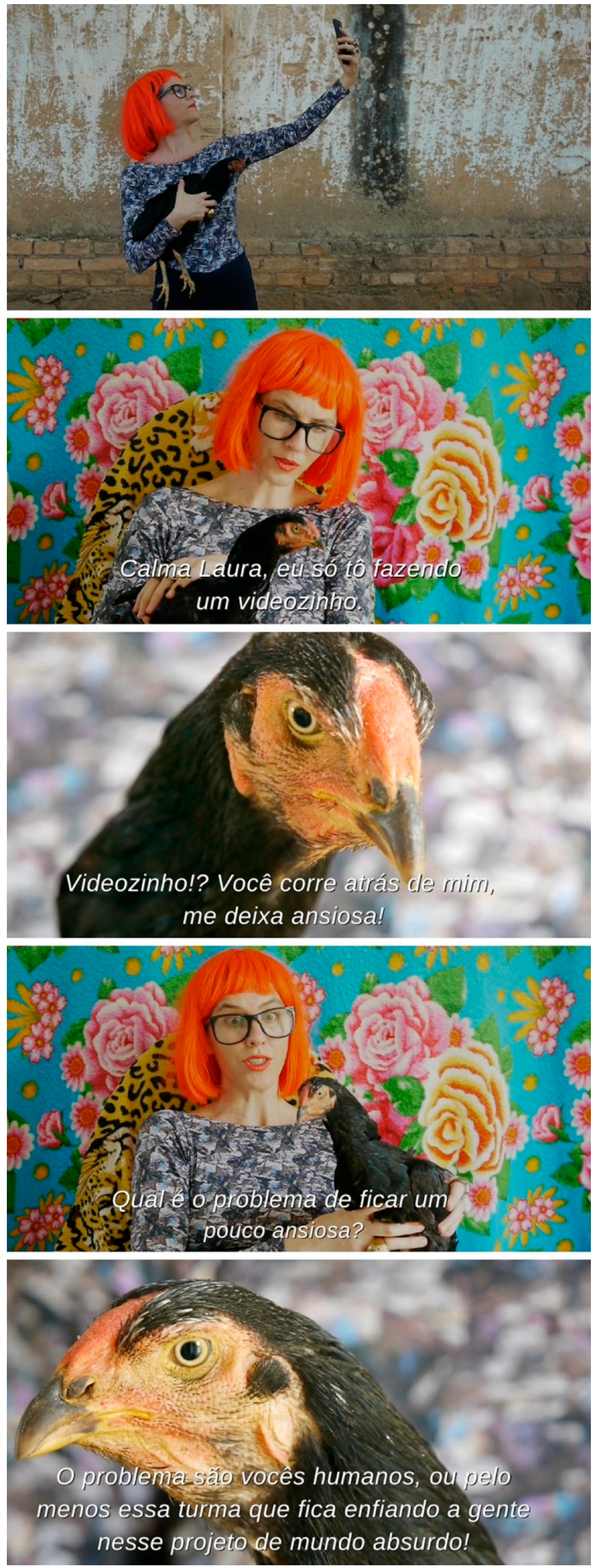

Olá pessoas, bem vindos, bem vindas, bem vindes, ao SaiFetiche, o canal da verdade, a verdade-verdadeira, onde tudo será revelado, aqui neste volume do DAT, ou no YouTube ${ }^{1}$ de meu deus-Google. Ai, um deus-digital, não é perfeito?

Meu nome é Juxara e estou aqui pra acabar com todos os seus fetiches. Isso mesmo, não deixarei pedra sobre pedra. Todas essas camadas, essa neblina, que vai ofuscando a gente, bem sedutoramente, encobrindo a origem das relações de poder, pra que a gente não consiga mais enxergar as raízes profundas, estruturais e estruturantes, desse sistema que promete tantas "liberdades", cheio de possibilidades, cheio de chupetinhas deliciosas, que nos docilizam, nos entorpecem e nos domesticam pra que a gente se aliene de toda a violência que tá por traz da produção de cada chupetinha, oferecida, aceita, desejada e consumida. Inclusive essa chupetinha que digitaliza e televisiona tudo nessa vida.

Hoje falaremos sobre "Capitalismo de Vigilância", conceito cunhado pela pensadora americana Shoshana Zuboff ${ }^{2}$ (2018), que no artigo Big other: Capitalismo de vigilância e perspectivas para uma civilização de informação ${ }^{3}$ reflete sobre todas as etapas envolvidas no gigante armazenamento e venda de nossos dados, chamado de Big-Data. Logo no inicio do artigo, ela faz uma distinção importante. Para ela, o Big-Data não é um objeto isolado, ou seja, uma consequência inevitável do rolo-compressor tecnológico e que possui vida própria, como se fosse autônomo e exterior ao campo social. Ao contrário, ela entende que o Big-Data tem origem no social e é justamente ali (ou aqui) que devemos encontrá-lo e estudá-lo. Shoshana (2018) diz o seguinte: "Explorarei então a proposta de que o Big-Data é, acima de tudo, o componente fundamental de uma nova lógica de acumulação, profundamente intencional, e com importantes consequências que chamo de "capitalismo de vigilância"(ZUBOFF, 2018, p.18).

Fig 1. Juxara e Laura

Fonte: SaiFetiche. Disponível em https://www.youtube.com/ watch?v=EX6Y6Uj8CJk\&t=763s 

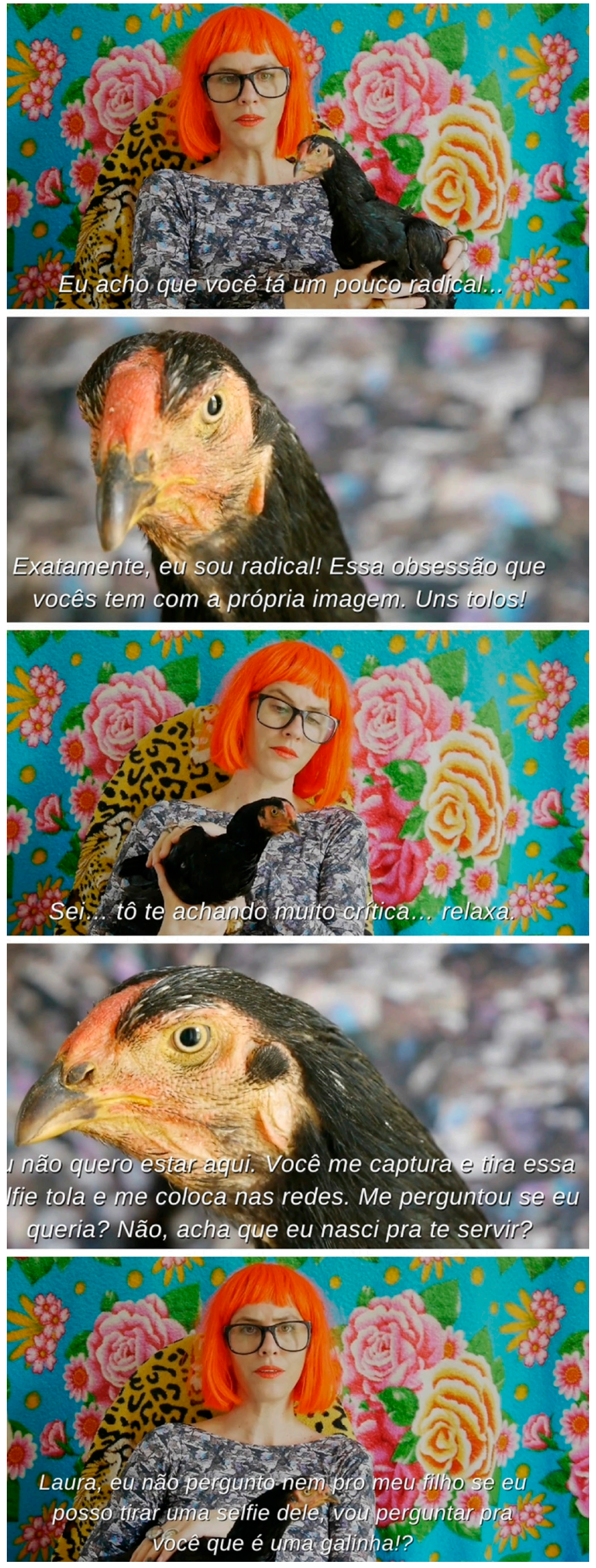

A principal tarefa da autora nesse artigo, é ajudar a gente a entender, passo a passo, o foco principal dessa nova forma de capitalismo da informação, ou seja: o de produzir receitas e controle de mercado. E pra isso ela usa como base de análise dois documentos escritos por Hal Varian (2014), nada mais nada menos do que o principal economista da Google. Isso significa que Shoshanna (2018) usa as próprias palavras de Varian - palavras que celebram o sucesso de uma empresa como a Google - para expor e denunciar como esse sucesso todo acontece na verdade, às nossas custas.

Não vou dar conta de explicar tudo aqui em detalhes, porque senão fica muito longo, e já me disseram que vocês desengajam rápido. Para quem quiser aprofundar, existem referências no final do texto ${ }^{4}$, que me ajudaram a entender esse abismo anestésico e, ao mesmo tempo, acelerador do Big-Data.

Dados. Vamos falar sobre os dados. Existem cinco fontes fundamentais que compõem o Big-Data. A primeira fonte são os dados derivados de transações econômicas mediados por computadores, ou seja, a informatização da economia em si, e todos os registros criados pelos computadores a cada transação econômica que é feita. A segunda fonte de dados, e que cresce exponencialmente, são os dados de bilhões de sensores incorporados em uma ampla gama de objetos, corpos e lugares, a chamada "internet das coisas". Nela, a interconexão digital de objetos cotidianos com a internet é capaz de reunir e de transmitir dados, ou seja, você com seu drone para fotografar e filmar os amigos no churras, ou usando aquele relógio high tech que mede sua pressão na academia, ou você na viagem para a praia com o seu carro automatizado e conectado na internet onde você faz tudo ao mesmo tempo, escuta música, se guia pelo googlemaps, fala com a amiga no whatsapp, assim tudo ao mesmo tempo mesmo que é mais eficaz, ou ainda fazendo aquela consulta no seu plano particular que usa nano

Fig 2. Juxara e Laura

Fonte: SaiFetiche. Disponível em https://www.youtube.com/ watch?v=EX6Y6Uj8CJk\&t=763s 
partículas para patrulhar seu corpo, a procura de doenças. Ou ainda quando você liga todos os seus dispositivos para o monitoramento do lar, sejam eles as câmeras de segurança do jardim ou o seu aspirador de pó digital novo. Uma terceira fonte de coleta flui de banco de dados governamentais e corporativos, ou seja, você lá fazendo a sua compra online com cartão de crédito, deixando o seu CPF na farmácia pra ganhar aquele descontinho, ou fazendo o seu registro fiscal no portal da receita federal, ou ainda quando compra suas passagens de avião, quando aciona seu plano de saúde, seu seguro, empresas de comunicação, entre muitos outros. Uma quarta fonte de dados flui das câmeras de vigilância, públicas e privadas, incluindo qualquer coisa desde smartphones até satélites, do Google Street View ao Google Earth. E por fim a quinta principal parte de fonte de dados, que é todo o acesso, indexação e buscas na internet, pesquisas do Google, páginas do Facebook, vídeos do YouTube, Blogs, redes, comunidades de amigos e estranhos.

Todos esses circuitos de interação através das redes sociais, que gerenciam o que Shoshanna (2018) chama de "subjetividade de autodeterminação" impulsionam "uma espécie de exultação de caça, coleta e compartilhamento de informações para todos os propósitos, ou mesmo pra nenhum" (ZUBOFF, 2018, p.31). Todas essas atividades são "apenas" a quinta fonte principal pro acúmulo de Big-Data mas, na minha pesquisa, fundamentais para a continuidade, regularidade, aprofundamento e manutenção de um processo de extração e análise dos nossos dados.

É através dessas atividades cotidianas que a lógica das redes opera na, e através da nossa subjetividade, garantindo que não haja muita, senão nenhuma, resistência às infrações e abusos corporativos e governamentais. Abusos, camuflados pelas praticidades, possibilidade de comunicação e conectividade, oferecidos pelos aplicativos, plataformas de compartilhamento e redes sociais. Diariamente sucumbimos à vigilância imposta por essas ferramentas tecnológicas. Não só por praticidade ou busca por uma vida eficaz, mas justamente, porque passamos a nos entender enquanto sujeitos no mundo, a partir da própria lógica desses contextos virtuais. Aqui, quando falo de um "nós", é porque, apesar das importantes diferenças de classe, raça, gênero e localidade geográfica que ocupam as redes, somos todos, todas e todes a própria mercadoria. Ou seja, aqueles que, ao consumir e produzir nas redes, geram dados e mais dados para acumulação do Big-Data. Dados que são vendidos para as empresas de marketing por grandes corporações como a Google e o Facebook. Nós, os ditos "usuários", não somos os clientes dessas redes. Os clientes são as empresas que compram nossos dados.

Não somos somente consumidores, nem produtores. Somos "prossumidores". O famoso dois em um tão lucrativo para o acúmulo de capital das megacorporações, para as quais trabalhamos de graça. E para otimizar o combo de exploração da nossa força de trabalho, somos fundamentalmente a mercadoria em si. 
No livro Vida para Consumo (2008), o filósofo polonês Zigmund Bauman, ajuda a entender melhor o papel dos "prossumidores" em uma sociedade de consumo, fortalecida e exacerbada pelas redes sociais. Ele faz uma comparação entre a noção de "Fetichismo da Mercadoria" de Karl Marx (1867) e o que ele, Bauman (2008), chama de "Fetichismo da Subjetividade." Em breves palavras, o Fetichismo da Mercadoria, serve para esconder todas as relações de trabalho implicadas na produção da mercadoria. Agora imagina você lá no mercado comprando seus ovos. Você pensa sobre todas as galinhas em cima do coco e xixi umas das outras, entulhadas nas gaiolas, recebendo doses regulares de antibióticos para que não adoeçam e produzam o maior número de ovos possíveis? Ou nos ovos que deram pintinhos machos são gaseados em incubação ou triturados vivos pra virar seu delicioso nugget. Pensa nisso? Não né!? Você está lá pensando no omelete!

Você também não deve pensar em todos os outros trabalhadores e trabalhadoras precarizados, explorados e pressionados pelas demandas de produtividade e competitividade do mercado, para que você possa consumir diariamente um omelete bem gostoso logo pela manhã. Você não vai pensar em tudo isso quando olhar para caixa de ovos, você vai pensar no café da manhã, com sua família, todos sorridentes, tipo o café da manhã de comercial, onde o omelete que chega a mesa é simplesmente um omelete.

Já o Fetichismo da Subjetividade, serve para esconder todas as relações de mercantilização implicadas na construção de identidades. Imagina você postando a fotinha do seu filhote ou filhota nas redes sociais. Vai pensar naquilo como dado sendo produzido por você mesma, que será extraído, vendido, analisado e convertido em um novo produto para que mamães, papais e crianças, desejem e consumam novas chupetinhas? Não, você vai fotografar e postar nas redes sociais como um ato de autodeterminação, expressão, compartilhamento espontâneo de uma vida corriqueira e comum.

As mídias sociais não são meras ferramentas de comunicação, mas fundamentalmente ferramentas de vigilância, manutenção e produção de comportamento, utilizadas pelas corporações paras quais trabalhamos de graça. Somos prossumidores de uma subjetividade que vai se tornando fetiche, à medida que esconde todas as relações de mercantilização que estão por trás de nossa construção enquanto sujeitos nas mídias sociais e fora delas. O que estamos fazendo quando nos encontramos presencialmente? Documentando e postando nas redes. É o fetichismo da subjetividade, no qual, como diz Bauman (2008, p.18): "na sociedade de consumidores ninguém pode virar sujeito sem antes virar mercadoria".

Nesse momento de mundo, no meio de uma pandemia ${ }^{5}$, está perfeito para que essa lógica se acentue vertiginosamente. A gente precisa da internet e dos serviços online mais do que nunca e as grandes corporações que dominam a internet usam isso pra nos vigiar. Se alguém aqui, que teve ou ainda tem o privilégio de ficar em casa, acha que estamos em algum tipo de suspensão ou pausa da lógica que nos trouxe até aqui, está dopado pela mais tóxica ilusão. Nunca estivemos tão produtivos nas redes, dopados pela praticidade virtual e exaustos pela produtividade intensa. 
É com essa isca da "autodeterminação" que as redes jogam e pescam a gente, que nem pesca predatória mesmo. E essa promessa de autonomia, comunicação, expressão é perfeita para que a gente se sinta importante, reconhecidos, reconhecidas, reconhecides. E em troca, produzimos incessantemente, escravinhas das chibatadas do algoritmo, operades pela demanda das empresas que querem comprar nossos dados e, em troca, nos ofertar mais e mais chupetas.

É uma fórmula que se quer infalível e ela acontece por exemplo no YouTube, onde "Você televisiona", "Você transmite", onde é "Você na telinha". No YouTube a gente é versátil, podemos, ou melhor devemos, ser "tudo". Exatamente como a versatilidade do capitalismo neoliberal impõe, ou melhor, tal como o capitalismo de vigilância nos suga, acaba com a gente. Você acorda e nem olha mais pela janela, já está lá no whatsapp, brigando com alguém, correndo para ver se tem mais um like, um seguidor (e não adianta dizer que você tá imune a essa porra toda, porque não está, inconsciente ou quimicamente, você está lá sim, pensando no like, no seguidor, ou ainda viciado na dopamina produzida no seu cérebro a cada like recebido. Esses sistemas que "qualificam" nossos posts foram muito bem pensados para que a gente siga grudado na tela, a espera de mais likes. 0 like não é somente um dado que impulsiona seu canal, mas te impulsiona subjetivamente. A dose de dopamina do like é curta, efêmera e, portanto, vai te deixar querendo sempre mais, mas nunca saciado.

Está aí, a lógica fundamental do capitalismo de vigilância, no que se refere ao controle e gerenciamento das nossas subjetividades: estarmos sempre mobilizados pelo desejo de algo que terminará instantaneamente no exato momento de seu consumo. Não há falta possível, podemos desejar, "ter" e "ser" tudo, desde que engajados, autorizados e incluídos na sociedade de consumidores. Ou ainda, manter a falta desejante, sempre querendo, sempre querendo, algo que nunca saciará, porque logo termina, no exato momento de seu consumo. É a alma do negócio no capitalismo. E a promessa de que essa falta seja suprida será sempre insuficiente, porque o desejo já está logo desejando a próxima chupetinha a ser consumida. o problema não é o desejo e a falta em si, sentir falta e desejar nos impulsiona na vida, nas relações e afetos. $O$ problema é exatamente como desejo e falta são instrumentalizados e gerenciados na lógica do capital. É nessa chave da subjetividade que o capitalismo de vigilância transforma seus pré-requisitos funcionais em motivos comportamentais de seus atores. Assim como em qualquer sistema social que se quer insuperável.

A nossa subjetividade vai sendo colonizada intensamente pela lógica das redes sociais, para que não haja resistência alguma a todas as promessas e chupetas que a praticidade online oferece. O problema não são as praticidades oferecidas, mas aquilo que devemos dar em troca delas. $O$ que damos em troca dessas praticidades, não são somente nossos dados, mas a nossa anestesia cognitiva. Olhar para essa anestesia com cuidado crítico é urgente. 
Anestesia cognitiva, porque sabemos que somos vigiados, mas há "aquele gozo" imediato no acesso às redes, ou a demanda por praticidade são tão acelerados, que clicamos no botãozinho "aceitar" de imediato, todo e qualquer contrato de acesso virtual, porque de fato, os contratos não são mútuos, não nos dão escolha alguma, é ou aceita ou não navega, e então aceitamos. Está lá desesperada no aeroporto esperando o seu voo para Cancum, aceita a porra toda.

Todas essas cotidianidades da navegação online, suas ações e discursos, configuram o chamado "small data", mediado por computadores no desenrolar da vida prática. O Big-Data é constituído, em larga medida, pela extração desse "small data". É nessa reatividade da vida cotidiana, em que "aceitamos" esses contratos impostos pelas grandes corporações para que possamos navegar nas redes, que o Big-Data vai bombando até ficar bem gigantesco, grande, poderoso, quase um novo petróleo para dinâmica geopolítica. Olha que loucura. E enquanto isso, o algoritmo dessa máquina vai subjugando a gente na lógica de produção ininterrupta, sempre disponíveis, sempre, sempre. Como diz Shoshanna (2018): "Nada é trivial ou efêmero em excesso para essa colheita: as "curtidas" do Facebook, as buscas no Google, e-mails, textos, fotos, músicas e vídeos, localizações, padrões de comunicação, redes, compras, movimentos, todos os cliques, palavras com erros ortográficos, visualizações de páginas e muito mais" (ZUBOFF, 2018, p.31).

Porque, é claro, no YouTube tudo pode. Direita, esquerda, centro, centrão, centrinho, centrásso, cetrífuga, estamos aí, frentes amplas vazias, mas com um efeito midiático ó, arrasa! Coloca tudo no mesmo pote, joga aqui e manda pra deus-silicon-valey. Tá ótimo. Tudo pode, mas nem tudo monetiza. Porque será que a extrema direita é tão grande nas redes sociais?

Mesmo que de alguma forma conscientes sobre todo esse processo de vigilância constante, há um apelo ideológico nas redes, seu fetichismo, que nos faz acreditar que ainda sim podemos falar o que pensamos. Apegados nessa "crença", a gente segue se expressando, na ilusão de que o tipo de comunicação oferecido nessas plataformas pode nos garantir alguma brecha fora da lógica do capital. Mas só que não. Enquanto ficamos gritando "expressão", e muitas vezes tentando driblar a lógica algorítmica - já que muitos conteúdos são sabotados e invisibilizados porque não monetizam tanto para as grandes corporações - nossos dados são extraídos, minerados, coletados, analisados numa espiral de controle empresarial e estatal, e que traduzem nossos dados em formato de produto, continuamente ofertados na nossa navegação online, para que a gente siga consumindo mais e mais novas chupetinhas.

É cíclico. Talvez um oroborus ${ }^{6}$ do capitalismo, onde, entre exibicionismo e vigilância, produzimos. À medida em que acredito construir uma identidade na internet, uma subjetividade virtual, fortaleço a máquina corporativa que me vigia, vende meus dados para empresas que traduzem minha subjetividade em novos produtos (sejam eles serviços, aplicativos, celebridades, detergentes, geladeiras, carros ou balas) e me ofertam todas essas 
possibilidades prescritas daquilo que eu devo consumir, para então poder "ser". E a gente expressa (quer dizer, produz) com música, filtro, emoticom, foto dos filhos, filhas, galinha, papagaio, cachorro, gatinho, pudim, jardim, o azulejo do banheiro... São tantas as possibilidades que fico até sem saber assim o que escolher nesse mar de escolhas, já feitas por mim. É como o ápice da liberdade prescrita. Posso tudo, ainda mais sendo branca desse jeito... Ninguém me segura. Vou bombar aqui nas redes. Aqui, onde todos, todas e todes nos tornamos essas cabeças falantes. E nesse melodrama das cabeças, no máximo o torso, driblamos a carência de um tipo de contato social durante a pandemia, enquanto garantimos o crescimento bilionário dessas mega corporações, já que estamos todo prontos e sendentos pra nos tornarmos esses coaches do eu, o euzinho bem individual, dando dicas de vida, amor, família, cuidados veterinários, jardinagem, política e etc..

Hal Varian, aquele economista da Google que mencionei no inicio desse texto, e que escreve os documentos analisados por Shoshanna (2018), aponta as oportunidades de negócios associados aos novos fluxos de dados. Ele deixa claro que os "experimentos contínuos" da Google estão no deslocamento da análise de dados a posteriori. Ou seja, em pouquíssimas palavras: se até agora podemos fazer uma pergunta ao Google, num futuro próximo, ele responderá sua pergunta antes mesmo que você a formule. Baseado no aprimoramento da extração, análise de dados e predição de comportamento, Varian (2014) celebra o que ele chama de "Google Now", como recurso que será "vital" na vida das pessoas comuns. Seria essa, a maximização do que Shoshanna (2018) chama de "Big-Other" (um grande-outro) essa entidade virtual, que nos aparece cada mais como um novo tipo de Deus? Varian (2014) menciona que a melhor maneira de prever o futuro é observar o que as pessoas ricas possuem, porque é isso o que as pessoas de classe média e pobres irão desejar. "O que as pessoas ricas tem agora?" ele pergunta. "Assistentes pessoais" é sua resposta. A solução? "É o Google Now", diz ele. 0 que o economista da Google prevê, é que o Google Now será indispensável na luta por uma vida mais eficaz e que, nas palavras dele, "as pessoas comuns concordarão em pagar o preço da invasão de privacidade" (Ibid. p. 30).

o que estou descrevendo é mais um dos muitos exemplos, nos quais o capitalismo se mostra de fato totalizante e capaz de interpelar todas as instancias da vida, de nossos afetos, formas de sociabilização e de como subjetivamos o mundo. Não seria diferente com a internet. Então, sem heroísmo, ingenuidade ou moralismo, ao pensar que ficar totalmente fora das redes sociais seria, talvez, uma solução. Isto porque de fato, as redes ainda carregam capacidade de produzir conexão entre a imensa diversidade de pessoas no mundo. Além disso, sem as redes sociais, essa diversidade de pessoas não teria acesso a muitos conteúdos, como esse texto por exemplo, e nem mesmo a possibilidade de mobilizar resistências e redes de solidariedade importantes. Ou ainda, devemos estar atentos, atentas e atentes para não cair na ilusão de que poderíamos estar nas redes produzindo conteúdo e, ao mesmo tempo, imunes a todas as cooptações implicadas no contexto 
de uma internet corporativizada, como a atual. Ou a ilusão de que apenas com regulamentações, a internet poderia escapar dessa lógica de acumulação e mercantilização dos nossos dados. Isso seria como uma espécie de reformismo na internet, um aparato legislador que não daria conta de acabar com um problema que é sistêmico e que, portanto, precisa ser revolucionado de forma antisistêmica.

Ora, sabemos muito bem como o sistema capitalista dá conta de instrumentalizar regulamentações legais a seu favor. Basta notar, como uma mega corporação como a Google já calcula em seus gastos, todas as indenizações que porventura precisem pagar, quando são denunciadas por infrações. Estes gastos sempre serão infinitamente menores do que o seu acúmulo de capital. Ou ainda, um outro tipo de ilusão, é a ideia de que não deveríamos ocupar esse espaço, um certo puritanismo, a crença de que haveria um fora total, um contexto de comunicação em larga escala, imune às cooptações do capitalismo. Lidar com todas as contradições envolvidas na produção de conteúdo sobre Marxismo, por exemplo, em uma plataforma como o YouTube, gerenciada por uma das maiores corporações do mundo como a Google, significa nos apropriarmos de uma ferramenta capitalista, para mobilizar sua própria implosão.

Então, não seria a implosão do YouTube, mas da lógica econômica que o coopta. E nesse sentido, é sempre fundamental lembrar e relembrar que precisamos inverter a lógica de vigilância. Precisamos vigiar e denunciar os poderosos e proteger a privacidade dos mais fracos no mundo. $\mathrm{Ou}$ ainda, devemos tentar aplicar radicalmente a máxima cypherpunk: "Privacidade para os fracos e transparência para os poderosos" (ASSANGE, 2013). Para que ferramentas como o YouTube, também funcionais na atualização do capitalismo, possam ser apropriadas por aqueles que querem superar o sistema atual. Precisamos de atenção constante e redobrada, sobre como o fetichismo dessas ferramentas quer nos anestesiar e nos entorpecer, para não enxergarmos mais os processos históricos da internet e da revolução tecnológica, sempre em resistência e, ao mesmo tempo, simbiose com o capitalismo. Precisamos entender onde estamos agora para podermos desenhar um horizonte que nos mobilize.

O cenário não está muito animador mesmo. Alias, vale lembrar que se tem alguma coisa que sabemos hoje sobre a fragilidade da segurança em computadores, todo o sistema de vigilância que opera a coleta e a análise de dados através da internet das coisas e sua navegação nas redes sociais é graças a ao ativista e jornalista australiano Julian Assange, co-criador do Wikileaks ${ }^{7}$, e que está sendo julgado na Inglaterra e provavelmente será extraditado para os Estados Unidos e condenado a 175 anos de prisão em isolamento. E por fazer o que? Jornalismo. Assange será julgado por receber e divulgar provas, trazidas por Chelsea Manning e Edward Snowden ${ }^{8}$, sobre os crimes cometidos pelos Estados Unidos. Será julgado por revelar o que os Estados Unidos não querem que seja revelado. E tem muita coisa que os E.U.A. não querem revelar, desde o assassinato de civis pelas tropas esta- 
dunidenses na guerra do Iraque, como a famosa execução via helicóptero Apache, até os modos de usar a América Latina como grande laboratório de guerra híbrida9 . Assange está sendo julgado por criar um contexto onde todos esses crimes pudessem ser expostos. Está sendo julgado por ter deixado claro que navegamos online como se fôssemos zumbis em estradas vigiadas com câmeras a cada milímetro, pegada no chão e nuvem no céu; ele será julgado enquanto atuamos como se esses abusos fossem pouco importantes, ou simplesmente mais um abuso, já que são tantos. E então preferimos fazer a escolha cotidiana de se autovigiar, sem nem mesmo resistir às "estradas vigiadas" que as redes representam, já que construímos nosso próprio "quintal" nas redes, convidamos nossos amigues para tirar a roupa ali, e claro, fazermos uma selfie. Mas mais importante: Assange está sendo julgado - e já condenado a todos os tipos de tortura psicológica - por nos mostrar uma potente brecha de resistência à constante vigilância e mercantilização de nossos dados. Ele está sendo julgado, por tentar mostrar que, contra os algoritmos corporativos, podemos nos munir de criptografias potentes e seguras. É mais fácil criptografar informações do que descriptografá-las.

E sobre como uma sociedade capitalista constrói seus heróis e vilões, Assange nos faz uma pergunta: "Quais são as diferenças entre o empresário e co-fundador do FaceBook, Mark Zuckerberg e eu?" E ele mesmo responde: "Eu forneço informações privadas sobre empresas para você de graça e sou um vilão. Zuckerberg oferece suas informações privadas a empresas por dinheiro, e ele é o Homem do Ano."10

O canal SaiFetiche, do YouTube é um disparador, para a gente acabar com os véus de fetichismo nas redes e para que possamos construir resistências propositivas nas brechas que ainda nos restam. Tem brecha? Lembre-se, não há fora total. Já estamos submersos nessa. Faz tempo. E o futuro, não é nada promissor. Então falar sobre "verdades-verdadeiras", é falar de todas as contradições em um sistema totalizante, que nos coopta a cada respiro, e dos quais somos cúmplices, cotidianamente. Então, termino aqui por hoje. Seguimos no canal, com mais Saifetiche, o canal da verdade, a verdade-verdadeira, onde tudo será revelado. Não desengajem, apareçam lá, me curtam, dá o like, comenta, acessa o sininho, lambe a tela, e vê se não dorme. 


\begin{abstract}
4 Além das referências do texto, deixo aqui outros links interessantes: Tecnopolíticas da Vigilância / Debate de Lançamento / Fernanda Bruno, Bruno Cardoso, Marta Kanashiro, Luciana Guilhon e Lucas Melgaço (orgs.) https://www.youtube.com/watch?v=73IRwaZoc_0\&t=1590s ; A Internet tragada pelo Capitalismo de Vigilância? | INTERNET AMEAÇADA / Outras Palavras: https://www.youtube.com/watch?v=0Zul1hERCA0 ; A INTERNET É O NOVO ÓPIO DO POVO? \#CaféBolchevique com Mauro lasi: https://www.youtube.com/results?search_query=mauro+iasi+capitalismo+de+vigil\%c3\%A2ncia . Acessos em: 22 abr. 2021.

5 A pandemia do Coronavirus SARS COV-19, declarada em 11/03/2020. Dados disponíveis em https://www.unasus.gov.br/noticia/organizacao-mundial-de-saude-declara-pandemia-de-coronavirus . Acesso em: 15 abr. 2021

60 termo vem do grego o pá: 'cauda' + ßópos 'consumo'; É um conceito simbolizado por uma serpente - ou por um dragão - que morde a própria cauda. Simboliza ciclos voltados para si mesmo, um fechamento do próprio ciclo, o eterno retorno.

7 https://wikileaks.org/ . Organização transnacional sem fins lucrativos, sediada na Suécia, baseada em vários softwares, que publica postagens de fontes anônimas, documentos, fotos e informações confidenciais, vazadas de governos ou empresas, sobre assuntos sensíveis.

8 Outras informações sobre o caso, ver https://www.bbc.com/portuguese/noticias/2013/12/131224_whistleblowers_pu_dg. Acesso em: 22 abr. 2021

9 É um modelo de "guerra indireta", no qual "as tradicionais ocupações militares podem dar lugar a golpes e operações indiretas para troca de regime". Remete-se às diferentes estratégias, além das táticas político-militares estado-unidenses, para substituir governos não alinhados à sua política, no século XXI. Korybko, A. GUERRAS HÍBRIDAS das revoluções coloridas aos golpes Expressão Popular São Paulo, 2018. Disponível em: http://resistir.info/livros/guerras_hibridas.pdf Acesso em: 22 abr. 2021

10 https://www.forbes.com/sites/kashmirhill/2010/12/19/julian-assange-knocks-mark-zuckerberg-on-saturday-night-live/?sh=74ecf2d27851 Acesso em: 22 abr. 2021
\end{abstract}

\section{Referências}

ASSANGE, Julian. Cypherpunks: liberdade e o futuro da internet. Tradução Cristina. Yamagami. São Paulo: Boitempo, 2013.

BAUMAN, Zygmunt. Vida para consumo: a transformação das pessoas em mercadoria. Rio de Janeiro: Zahar, 2008.

MARX, Karl. o Capital. Parte I. Capítulo 1: A Mercadoria. Primeira publicação, 1867. Portal Domínio Público, Marxists Internet Archives. Disponível em http://www.dominiopublico. gov.br/pesq... Acesso em: 23 abr. 2021.

ZUBOFF, Shoshana. Big other: capitalismo de vigilância e perspectivas para uma civilização de informação. In: BRUNO, F. et al. (orgs.). Tecnologias da vigilância: perspectivas da margem. Trad. H. M. Cardozo et al. São Paulo: Boitempo, 2018. p. 17-68.

VARIAN, Hal R. Computer Mediated Transactions. American Economic Review, v. 100, n. 2, 2010, p. 1-10; 2010. Disponível em: https://www.sfu.ca/ palys/Varian-2010- ComputerMediatedTransactions.pdf. Acesso em: 23 abr. 2021.

Recebido: 15 de fevereiro de 2021. VARIAN, Hal R. Beyond big data, Business Economics, v. 49, n. 1, 2014, p. 27-31. Disponível Aprovado: 05 de março de 2021. em https://link.springer.com/article/10.1057/be.2014.1 . Acesso em: 23 abr. 2021. 